\title{
A Two-Phase Numerical Model of Well Test Analysis to Characterize Formation Damage in Near-Well Regions of Injection Wells
}

\author{
Jia Zhang $\mathbb{D}^{1},{ }^{1}$ Shiqing Cheng $\left(\mathbb{D},{ }^{1}\right.$ Shiying Di $\mathbb{D}^{1},{\text { Zhanwu Gao } \mathbb{D}{ }^{2}{ }^{2} \text { Rui Yang, }}^{3}$ \\ and Pengliang $\mathrm{Cao}^{3}$ \\ ${ }^{1}$ State Key Laboratory of Petroleum Resources and Prospecting, China University of Petroleum, Beijing 102249, China \\ ${ }^{2}$ PetroChina Changqing Oilfield Company, Xi'an 710018, China \\ ${ }^{3}$ Gas Production Plant 5 of PetroChina Changqing Oilfield Company, Xi'an 710000, China
}

Correspondence should be addressed to Jia Zhang; 2017312042@student.cup.edu.cn and Shiqing Cheng; chengsq973@163.com

Received 22 December 2020; Revised 15 January 2021; Accepted 29 January 2021; Published 19 February 2021

Academic Editor: Weijun Shen

Copyright ( 2021 Jia Zhang et al. This is an open access article distributed under the Creative Commons Attribution License, which permits unrestricted use, distribution, and reproduction in any medium, provided the original work is properly cited.

\begin{abstract}
Formation damage usually occurs in near-well regions for injection wells completed in offshore oilfields under the development of line drive patterns. However, current works on characterizing the damage by well test analysis were basically focused on using single-phase analogy to solve two-phase flow issues, resulting in errors on the diagnosis and interpretation of transient pressure data. In this paper, we developed a two-phase model to simulate the pressure transient behavior of a water injection well in a multiwell system. To solve the model more efficiently, we used the finite volume method to discretize partially differential flow equations in a hybrid grid system, including both Cartesian and radial meshes. The fully implicit Newton-Raphson method was also employed to solve the equations in our model. With this methodology, we compared the resulting solutions with a commercial simulator. Our results keep a good agreement with the solutions from the simulator. We then graphed the solutions on a log-log plot and concluded that the effects of transitional zone and interwell interference can be individually identified by analyzing specific flow regimes on the plot. Further, seven scenarios were raised to understand the parameters which dominate the pressure transient behavior of these flow regimes. Finally, we showed a workflow and verified the applicability of our model by demonstrating a case study in a Chinese offshore oilfield. Our model provides a useful tool to reduce errors in the interpretation of pressure transient data derived from injection wells located in a line drive pattern.
\end{abstract}

\section{Introduction}

Currently, offshore oilfields have assumed a significant role in petroleum production. To improve oil recovery, line drive patterns have been widely employed in offshore oilfields, as shown in Figure 1. However, formation damage is quite common in near-well regions of injection wells in offshore oilfields due to interaction between injection water and clay minerals [1-12]. To characterize the formation damage and estimate reservoir properties, transient pressure data observed from the testing wells are usually interpreted by traditional pressure transient analysis models [13-22], which are simplified single-phase models divided into two or three regions according to the properties of formation and fluids.

However, the flow behaviors in such wells are much complicated than the situations assumed in the traditional composite model. As shown in Figure 2, saturation gradients are generated from water injection due to the different properties of injected water and reservoir fluids. There are saturation discontinuities between the region where the injected water completely floods and the region where the original fluids predominate. Hence, the results derived by the single-phase flow model will lead to large errors. To solve this problem, numerical well test techniques were developed to 


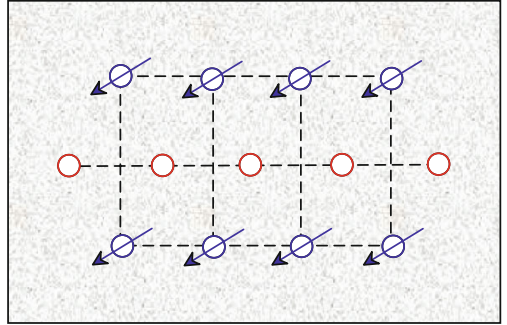

$\begin{array}{ll}\varnothing & \text { Injector } \\ \bigcirc & \text { Producer }\end{array}$

Figure 1: Schematic of the line drive pattern widely employed in offshore oilfields. The water injection wells are usually arranged in a straight line parallel to the production wells.

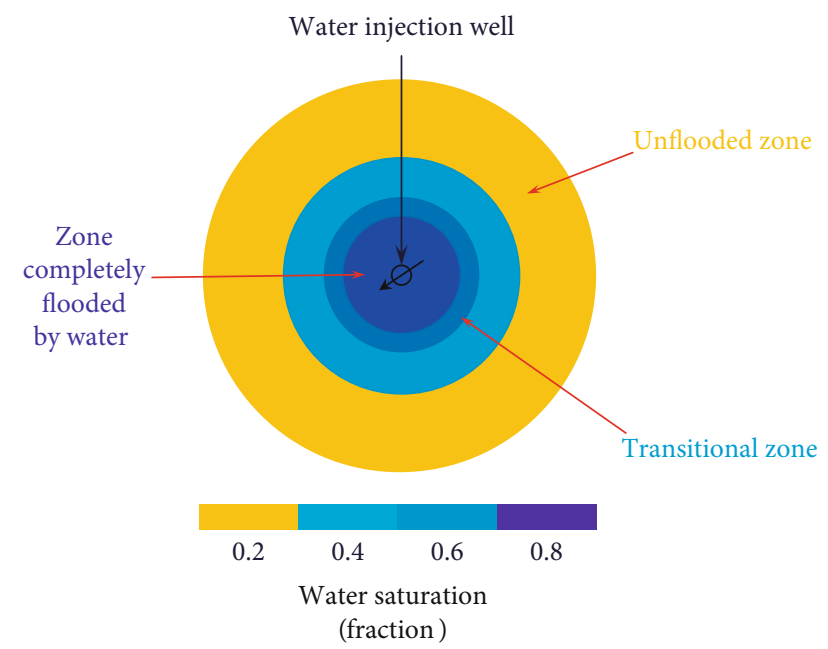

Figure 2: Schematic of fluid distribution around a water injection well. Saturation gradients are established by water injection due to the different properties of injected water and reservoir fluids. In the schematic, the residual oil saturation is 0.2 ; the irreducible water saturation is 0.2 . The injection well is at the center of the circle. The dark blue is a zone completely flooded by water. The orange is an unflooded zone. The light blue is the transitional zones between the unflooded zone and the zone completely flooded by water.

simulate the two-phase flow in the water-flooding system. Weinstein [23] presented a numerical model of two-phase flow to analyze the pressure data of falloff tests. However, he ignored the effect of the transitional zone between the zone completely flooded by water and the unflooded zone. After that, Sosa et al. [24] investigated the effect of saturation gradients on the pressure response of the falloff test by considering relative permeability characteristics with the aid of a two-phase numerical model, in which the influence of relative permeability characteristics, injection rate, and injection time on saturation gradients was analyzed. Yeh and Agarwal [25] developed a systematic method to analyze the pressure data from an injection well in a water-flooding system with multiple fluid banks with the assistance of a two-phase twodimensional model and discussed the characteristics of flow regimes of the zone completely flooded by water and the unflooded zone. Later, Warren [26] applied numerical solu- tions in pressure transient analysis and discussed the technical advantages of the numerical model in pressure transient analysis of two-phase flow. Liao and Liu [27] found that the pressure transient behavior of multilayer two-phase flow was similar to that of the single-phase flow in a dualporosity reservoir with a three-dimensional model of twophase flow in PEBI grids. Xiang et al. [28] studied the effect of different sets of oil relative permeabilities on the pressure transient behavior of a production well with a numerical model of two-phase flow in PEBI grids. Xu [29] presented an approach based on a theoretical developed by Thompson [30] to analyze the pressure response in the transition region of two-phase flow with the aid of a commercial simulator. Furthermore, two-phase numerical models applicable to formation damage were proposed. Jian and Xin [31] analyzed the influence of interwell heterogeneity on water flooding effectiveness with a numerical model of two-phase flow in a composite reservoir, which was divided according to permeability and water saturation distribution. Li et al. [32] estimated the formation damage with a numerical model of multiphase flow in a $\mathrm{CO}_{2}$ flooding system. Ouyang et al. [33] investigated the characteristics of a formation damaged zone with a numerical model of multiphase flow. However, the characteristics of the flow regime of the transitional zone were ignored in the above models of two-phase flow, which might be helpful in history matching.

Although the above models are satisfactory in the pressure transient analysis of single-well systems, the interference effect from adjacent injection wells can obscure or distort the pressure transient behavior of the testing well in multiwell systems, which is particularly pronounced in line drive patterns of offshore oilfields. Therefore, the interference should be considered for pressure transient analysis in multiwell systems, and different models were proposed in the past few decades. Onur et al. [34] investigated a single-phase flow model to analyze the pressure buildup response of a multiwell system containing producers. On this basis, Lin [35] raised a novel method for pressure transient behavior in a multiwell system consisting of both producers and injectors. More and more single-phase flow models for analyzing pressure transient behavior in multiwell systems have been developed [36-38]. However, these single-phase flow models are developed with idealized assumptions and not suitable for complicated cases. Hence, some scholars proposed numerical models for pressure transient analysis in multiwell systems. Zhang et al. [39] developed a numerical model of twophase flow in a multiwell system containing producers and investigated the effect of adjacent producers on pressure buildup behavior. Al-Wehaibi et al. [40] presented a numerical model for a multiwell system consisting of producers to match the pressure data obtained from an intelligent field system. Although these numerical models can be used in a multiwell system containing injectors, the effect of saturation gradients on the pressure transient behavior of water injection wells in a multiwell system has not been investigated.

In conclusion, the ignorance of the effect of the transitional zone or the interference of adjacent injectors in a multiwell system will lead to errors in transient pressure analysis. To solve this problem, a numerical model of two-phase flow 
is urgently needed to interpret the pressure data obtained from water injection wells in line drive patterns of offshore oilfields instead of oversimplified single-phase models.

The objective of this paper is to propose a numerical model of two-phase flow for well test interpretation in a multiwell system consisting of injectors, which takes into account the formation damage in the near-well zone of the testing injector. The model was validated by comparing with a commercial simulator. Additionally, although commercial simulators can simulate two-phase flow in reservoirs, they fail to take into account the influence of wellbore storage on the pressure transient response. Therefore, our model is still urgently needed for pressure transient analysis. After validation, we discussed the influence of the saturation gradients and interference from adjacent injectors on the pressure transient behavior of the testing injector. To demonstrate the practicability of the model, we interpreted the pressure data of a water injection well in a line drive pattern of a Chinese offshore oilfield.

\section{Model Development}

In this section, we present a numerical model of two-phase flow for well test interpretation in a multiwell system firstly. When it comes to the differentiation of the partially differential flow equations, finite difference method [41-48] and finite volume method [49-56] are both commonly employed in solving fluid flow equation systems. However, in unstructured grids, formulating the finite volume method is much easier. Therefore, we adopt finite volume method to discretize the flow equations in a hybrid grid system consisting of both Cartesian and radial meshes. After that, we solve the discrete equations with the fully implicit Newton-Raphson method.

2.1. Model Description. During the falloff test, the rate of the testing injector keeps constant before shut-in. Rates of adjacent injectors remain constant throughout the whole test. In this paper, we only focus on the interference of adjacent injectors in the line drive pattern because the rates of the injectors are commonly much higher than those of the producers in the pattern.

Figure 3 is the schematic of a physical model in which the testing well is a water injection well interfered by two adjacent injectors. Formation is divided into two regions. The area of formation damage is the inner zone (green); the remaining part is the outer zone (orange).

Our other basic assumptions are as follows:

(1) The reservoir is homogenous in each zone; the initial pressure and water saturation of the reservoir are distributed uniformly. External boundary of the reservoir is sealed

(2) Fluid flow is a two-phase flow in which the relative permeability of oil and water phase is taken into account. Capillary pressure is ignored in our model due to its quite limited effect on the pressure transient response in moderate-permeability or high-permeability offshore oilfields with water flooding

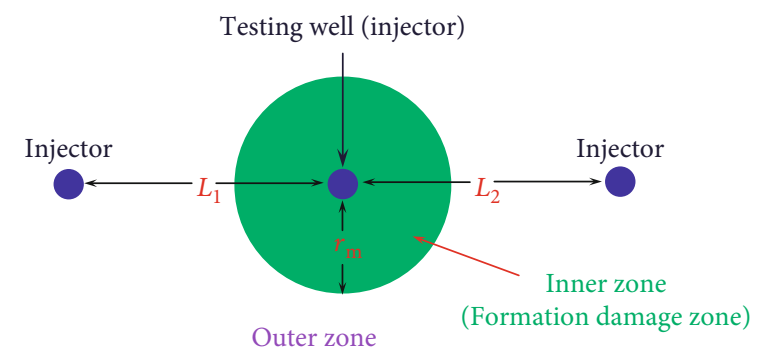

FIgURE 3: Schematic of the physical model. The green is the inner zone (formation damage zone), indicating the formation damage area. The orange is the outer zone, where permeability remains unchanged. $r_{m}$ is the radius of the inner region in the schematic. $L_{1}$ and $L_{2}$ denote the well spacing between the testing well and each adjacent injector.

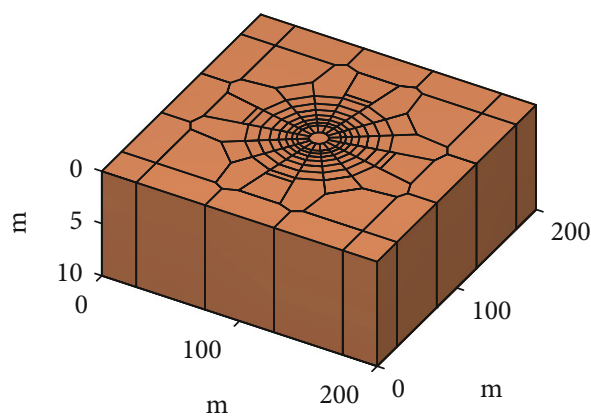

Figure 4: A hybrid grid system consisting of both Cartesian and radial meshes.

(3) Rocks and fluids in the reservoir are both slightly compressible. Viscosities of fluids are constant

2.2. Mathematical Model. With the above assumptions, we formulate the governing differential flow equations for the multiwell flow system [56]; the general flow equation for the oil/water phase can be written as

$$
\frac{\partial}{\partial t}\left(\phi b_{\alpha} S_{\alpha}\right)+\nabla \cdot\left(b_{\alpha} v_{\alpha}\right)-Q_{\alpha}=0, \alpha=\{o, w\},
$$

where $\phi$ is the rock porosity, $b_{\alpha}$ is the reciprocal of the oil/water formation volume factor, $S_{\alpha}$ is the oil/water saturation, $v_{\alpha}$ is the velocity of oil/water phase in porous media, and $Q_{\alpha}$ is the well flux of oil/water phase.

The fluid flow in the reservoir is assumed to follow the Darcy's law. Given that a two-phase flow issue is involved in this study, relative permeability should be taken into account in the flow equations. Therefore, the velocity can be replaced by the following equation.

$$
v_{\alpha}=-\frac{K k_{r \alpha}}{\mu_{\alpha}}\left(\nabla p_{\alpha}-\rho_{\alpha} g \nabla z\right), \quad K=\left\{\begin{array}{lll}
K_{1} & 0<r \leq r_{m}, \\
K_{2} & r>r_{m}, &
\end{array}\right.
$$

where $r_{m}$ is the radius of the inner region in the schematic of Figure $3, K_{1}$ is the permeability of the inner zone (formation 


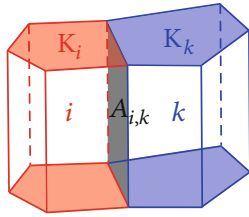

(a)

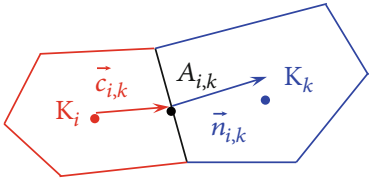

(b)

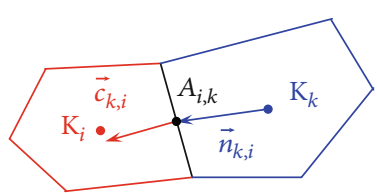

(c)

FIGURE 5: Two unstructured cells for calculating transmissibility in finite volume discretization. (a) Three-dimensional schematic of two adjacent unstructured cells. $\mathbf{K}_{i}$ is the permeability tensor of cell $i, \mathbf{K}_{k}$ is the permeability tensor of cell $k$, and $A_{i, k}$ is the area of the interior face between the two neighboring cells in (a). (b) Top view of (a) for calculating the one-sided transmissibility from cell $i$ to cell $k$ in finite volume discretization. $\vec{c}_{i, k}$ is the vector from the centroid of cell $i$ to the centroid of the face between the two neighboring cells in (a); $\vec{n}_{i, k}$ is the normal from the centroid of the interior face to cell $k$. (c) Top view of (a) for calculating the one-sided transmissibility from cell $k$ to cell $i$ in finite volume discretization. $\vec{n}_{k, i}$ is the vector from the centroid of cell $k$ to the centroid of the interior face between the two adjacent cells in (a); $\vec{c}_{k, i}$ is the normal from the centroid of the interior face to cell $i$.

damage zone), $K_{2}$ is the permeability of the outer zone, $p_{\alpha}$ is the pressure of oil/water phase in reservoir, $k_{r \alpha}$ is the relative permeability of oil/water phase, $\mu_{\alpha}$ is the viscosity of oil/water phase, $\rho_{\alpha}$ is the density of oil/water phase, $g$ is the gravity acceleration, and $z$ is the depth in gravity direction.

Since the capillary pressure is ignored in our model, the relation of oil-phase pressure and water-phase pressure is

$$
p_{w}=p_{o}
$$

Total rates of wells are known quantities in pressure transient analysis. However, oil flow rate and water flow rate in wellbores still need to be calculated.

$$
\begin{aligned}
Q_{s} & =\sum\left(Q_{w}+Q_{o}\right), \\
\lambda_{\alpha} & =\frac{k_{r \alpha}}{\mu_{\alpha}}, \\
Q_{\alpha} & =\frac{2 \pi K \lambda_{\alpha} h b_{\alpha}}{\left(\ln \left(r_{\mathrm{e}} / r_{w}\right)+S\right)}\left(p_{\mathrm{wf}}-p_{\alpha}\right)+\frac{\lambda_{\alpha}}{\sum \lambda_{\alpha}} C b_{\alpha} \frac{d p_{\mathrm{wf}}}{d t},
\end{aligned}
$$

where $Q_{s}$ is the total well flux of oil and water phase, $\lambda_{\alpha}$ is the ratio of relative permeability to viscosity for oil/water phase, $h$ is the thickness of formation, $r_{e}$ is the equivalent radius in well flux equation, $r_{w}$ is the wellbore radius, $S$ is the skin factor, $p_{\text {wf }}$ is the bottom-hole pressure, $C$ is the wellbore storage constant, and $t$ is the time.

2.3. Differentiation and Solution. We need to craft a grid system before the differential process. To compute the discrete equations more efficiently, we used a hybrid grid system consisting of both Cartesian and radial meshes (Figure 4). The unstructured refined radial meshes are distributed in the near-well region to improve the computing accuracy. The large Cartesian meshes are located far from the wellbore to reduce the computational time. The basic properties of each grid include cell $(c)$, face $(f)$, and node.

In our discretization process, we employ the discrete operators div and grad to represent divergence and gradient operators, respectively [57]. The div operator maps from face to cell. Subsequently, we will employ boldfaced letters to denote arrays of discrete quantities. For instance, we denote that $\mathbf{q}$ is the array of discrete fluxes, then $\mathbf{q}[f]$ is the discrete flux flowing from cell $C_{1}(f)$ to cell $C_{2}(f)$ across face $f$. The divergence of the flux confined to cell $c$ is

$\operatorname{div}(\mathbf{q})[c]=\sum_{f \in F(c)} \operatorname{sgn}(f) \mathbf{q}[f], \quad \operatorname{sgn}(f)= \begin{cases}1, & c=C_{1}(f), \\ -1, & c=C_{2}(f),\end{cases}$

where $F(c)$ is the set of all faces that make up cell $c$.

The discrete operator grad is a linear mapping from cell to face. If we define that $\mathbf{p}$ is the array of discrete pressures, then the pressure gradient restricted to face $f$ is

$$
\operatorname{grad}(\mathbf{p})[f]=\mathbf{p}\left[C_{2}(f)\right]-\mathbf{p}\left[C_{1}(f)\right]
$$

Additionally, we designate that $\mathbf{T}$ is the array of discrete transmissibilities across faces; then, $\mathbf{T}[f]$ is the transmissibility of face $f$. Figure 5 illustrates an example of two neighboring cells, which are used for introducing the procedure to calculate transmissibility in the discretized equations. More specifically, the one-sided transmissibility from cell $i$ to cell $k$ in finite volume discretization should be $[57,58]$

$$
T_{i, k}=A_{i, k} \mathbf{K}_{i} \frac{\vec{c}_{i, k} \vec{n}_{i, k}}{\left|\vec{c}_{i, k}\right|^{2}}
$$

Similarly, the one-sided transmissibility from cell $k$ to cell $i$ is

$$
T_{k, i}=A_{i, k} \mathbf{K}_{k} \frac{\vec{n}_{k, i} \vec{c}_{k, i}}{\left|\vec{n}_{k, i}\right|^{2}}
$$

where $A_{i, k}$ is the area of the interior face between the two neighboring cells in Figure 5(a), $\vec{n}_{i, k}$ is the normal from the centroid of the interior face to cell $k, \vec{c}_{i, k}$ is the vector from the centroid of cell $i$ to the centroid of the interior face, $\mathbf{K}_{i}$ is the permeability tensor of cell $i, \vec{n}_{k, i}$ is the vector from the centroid of cell $k$ to the centroid of the interior face, $\vec{c}_{k, i}$ 


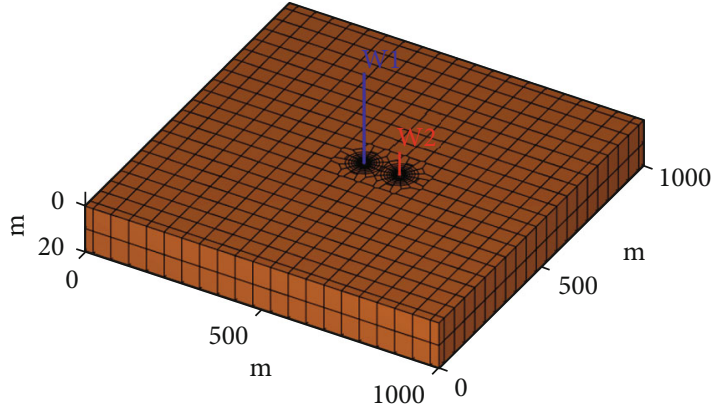

FIGURE 6: A reservoir with two wells. W1 is an injector; W2 is a producer. Well spacing between the two wells is $100 \mathrm{~m}$. The flow rates of the two wells are both $100 \mathrm{~m}^{3} / \mathrm{d}$.

is the normal from the centroid of the interior face to cell $i$, and $\mathbf{K}_{k}$ is the permeability tensor of cell $k$.

The transmissibility of the interior face between the two adjacent cells in Figure 5(a) is defined based on the above one-sided transmissibilities.

$$
T_{i k}=\left[T_{i, k}^{-1}+T_{k, i}^{-1}\right]^{-1} .
$$

Therefore, the flux passing through the face $f$ is

$$
\mathbf{q}[f]=-\mathbf{T}[f] \operatorname{grad}(\mathbf{p})[f] .
$$

According to the above discrete operators, the discrete form of equation (1) is

$$
\begin{aligned}
\mathbf{R}_{\alpha}^{n+1, l}= & \mathbf{V}[c] \frac{\left(\phi[c] \mathbf{b}_{\alpha}[c] \mathbf{S}_{\alpha}[c]\right)^{n+1, l}-\left(\boldsymbol{\phi}[c] \mathbf{b}_{\alpha}[c] \mathbf{S}_{\alpha}[c]\right)^{n}}{\Delta t^{n+1}} \\
& +\operatorname{div}\left(\mathbf{b}_{\alpha}[f] \mathbf{v}_{\alpha}[f]\right)^{n+1, l}-\left(\mathbf{Q}_{\alpha}[c]\right)^{n+1, l}=0,
\end{aligned}
$$

where $\mathbf{V}$ is the array of volumes of grids, $n$ is the time step, and $l$ is the iterating step of each time step.

Again, note that we employ boldfaced letters to define arrays of discrete quantities in discrete equations. $\mathbf{v}_{\alpha}[f]$ in equation (11) can be replaced by the following discrete expression

$$
\mathbf{v}_{\alpha}[f]=-\mathbf{T}[f] \boldsymbol{\lambda}_{\alpha}[f]\left\{\operatorname{grad}\left(\mathbf{p}_{\alpha}\right)[f]-g\left(\boldsymbol{\rho}_{\alpha}[f]\right) \operatorname{grad}(\mathbf{z})[f]\right\} .
$$

The discrete form of the well equation is

$$
\mathbf{R}_{q}^{n+1 . l}=\left(\mathbf{Q}_{s}[c]\right)^{n+1}-\sum_{j}\left(\mathbf{Q}_{\alpha}[c]\right)^{n+1, l}=0 .
$$
(13) is

The discrete expression of oil/water flow rate in equation

$$
\begin{aligned}
& \mathbf{Q}_{\alpha}^{n+1, l}=\left\{\frac{2 \pi \boldsymbol{\lambda}_{\alpha}[c] h \mathbf{b}_{\alpha}[c]}{\ln \left(r_{e} / r_{w}\right)+S}\right\}^{n+1, l}\left(\mathbf{p}_{w f}[c]-\mathbf{p}_{\alpha}[c]\right)^{n+1, l} \\
& +\left\{\frac{\boldsymbol{\lambda}_{\alpha}[c]}{\sum \boldsymbol{\lambda}_{\alpha}[c]} C \mathbf{b}_{\alpha}[c]\right\}^{n+1, l} \frac{\mathbf{p}_{w f}^{n+1, l}[c]-\mathbf{p}_{w f}^{n}[c]}{\Delta t^{n+1}} .
\end{aligned}
$$

TABLE 1: The basic parameters of the reservoir.

\begin{tabular}{lc}
\hline Parameters & Values \\
\hline Initial reservoir pressure, $\mathrm{MPa}$ & 20 \\
Well radius, m & 0.1 \\
Skin factor of injector, unitless & 0.1 \\
Skin factor of producer, unitless & 0.1 \\
Permeability of layer $1, \mathrm{D}$ & 0.1 \\
Permeability of layer $2, \mathrm{D}$ & 0.1 \\
Porosity, fraction & 0.3 \\
Rock compressibility, $\mathrm{MPa}^{-1}$ & 0.001 \\
Initial water saturation, fraction & 0.5 \\
Initial oil saturation, fraction & 0.5 \\
Oil viscosity, mPa $\cdot \mathrm{s}$ & 10 \\
Oil compressibility, $\mathrm{MPa}^{-1}$ & 0.001 \\
Oil volume factor, $\mathrm{m}^{3} / \mathrm{m}^{3}$ & 0.9 \\
Water viscosity, $\mathrm{mPa} \cdot \mathrm{s}$ & 1 \\
Water compressibility, $\mathrm{MPa}^{-1}$ & 0.0002 \\
Water volume factor, $\mathrm{m}^{3} / \mathrm{m}^{3}$ & 1 \\
\hline
\end{tabular}

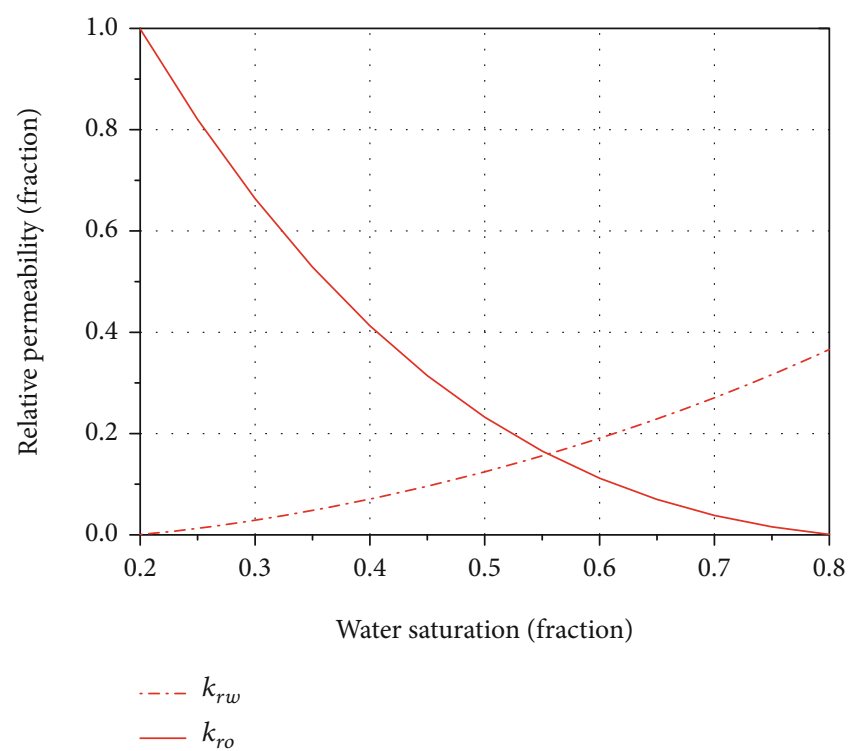

FIGURE 7: The relative permeability curves.

Coupling with equations (11)-(14), we obtain

$$
\mathbf{R}^{n+1, l}\left(\mathbf{X}^{n+1, l}\right)=\left(\mathbf{R}_{o}^{n+1, l}, \mathbf{R}_{w}^{n+1, l}, \mathbf{R}_{q}^{n+1, l}\right)^{T}=0,
$$

where $\mathbf{X}$ is the array of primary variables.

Fully implicit Newton-Raphson method is a standard and common method to solve the above nonlinear system. The iterative scheme of equation (15) is

$$
\frac{\partial \mathbf{R}_{\alpha}^{n+1 . l}\left(\mathbf{X}^{n+1, l}\right)}{\partial \mathbf{X}} \Delta \mathbf{X}^{n+1, l}=-\mathbf{R}_{\alpha}^{n+1 . l}\left(\mathbf{X}^{n+1, l}\right) .
$$

To ensure the precision of the Newton iteration, we 


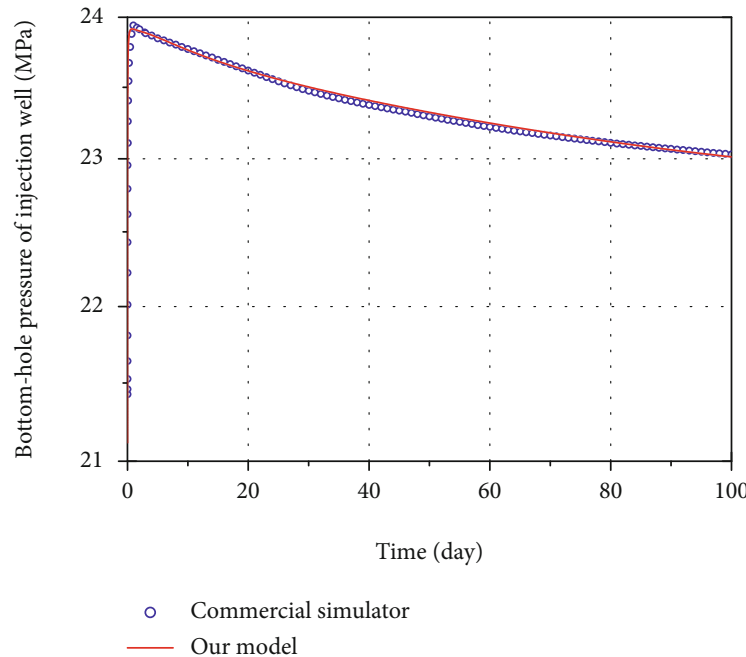

(a)

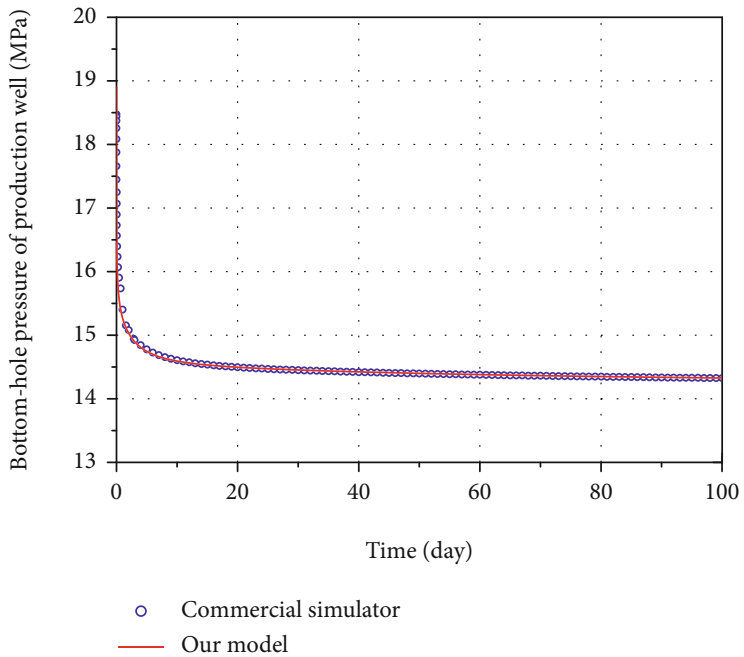

(b)

FIgURE 8: Comparison between our model and a commercial simulator: (a) bottom-hole pressures of an injection well computed by our model and a commercial simulator; (b) bottom-hole pressures of a production well computed by our model and a commercial simulator.

employ three constraint conditions to judge the convergence of the solution [57]. The first measure is the relative incremental error, which is developed based on the increment of the primary variables for each iteration step.

$$
\mathrm{IUV}=\left\|\frac{\Delta \mathbf{X}^{n+1, l}}{\mathbf{X}^{n}}\right\|_{\infty} .
$$

The second measure is the relative mass-balance error, which follows the mass balance.

$$
\mathrm{MB}_{\alpha}=\Delta t^{n+1} \frac{\sum \mathbf{R}_{\alpha}^{n+1 . l}}{\sum \boldsymbol{\Phi}^{n+1 . l}},
$$

where $\boldsymbol{\Phi}_{\alpha}$ is the array of quality of oil/water phase in cells.

The third measure is the maximum normalized residual, which reads as follows

$$
\mathrm{MV}_{\alpha}=\Delta t^{n+1} \max \left|\frac{\mathbf{R}_{\alpha}^{n+1 . l}}{\mathbf{\Phi}^{n+1 . l}}\right|
$$

We can compute the bottom-hole pressure at each time step to analyze the pressure transient behavior of testing wells by the above procedure.

\section{Model Validation}

The next consideration is the accuracy of our model. We craft an example to verify the numerical solution with a commercial simulator. Figure 6 is the schematic of a $1000 \mathrm{~m} \times 1000 \mathrm{~m} \times$ $20 \mathrm{~m}$ grid block reservoir model with hybrid grids (i.e., regular Cartesian and radial grids). The simulator to be compared just uses simple Cartesian grids with the same reservoir size. We set an injector and a producer in the two models, as shown in Figure 6, in which W1 refers to the injection well and W2 is the production well. Well spacing between the two wells is

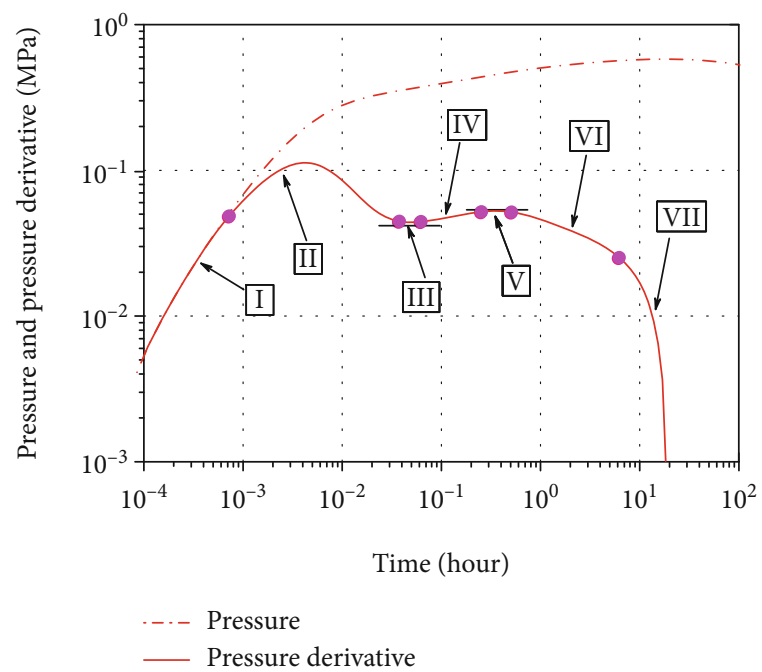

FIgURe 9: Type curve and flow regimes of our model. I is the flow regime of wellbore storage, II is the flow regime of wellbore damage, III is the first radial flow regime, IV is the flow regime of transitional zone caused by water injection before shut-in, $\mathrm{V}$ is the second radial flow regime, VI is the transitional flow regime of formation damage, and VII is the flow regime of interference from two adjacent injectors.

$100 \mathrm{~m}$. The basic reservoir and production parameters used in this validation process are listed in Table 1 . In addition, the relative permeability curves are shown in Figure 7 . The flow rates of the two wells are both $100 \mathrm{~m}^{3} / \mathrm{d}$. With the production of $100 \mathrm{~d}$, we compute bottom-hole pressures by the two approaches. Note that our goal in this validation should not focus on the effect of wellbore storage; hence, we ignore this effect in our validation.

As shown in Figure 8, the comparison results show that the bottom-hole pressures computed from the two approaches 


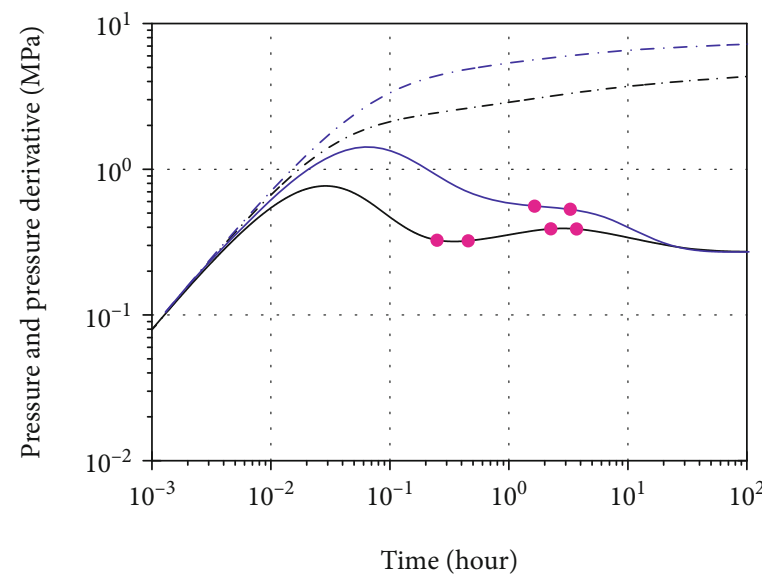

- Well test of two-phase flow

_ Well test of single-phase flow

(a)

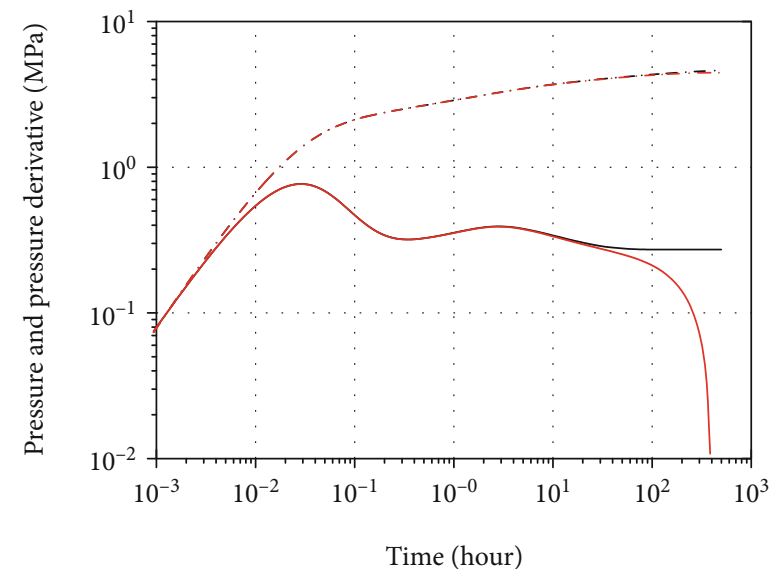

_ Well test of two-phase flow - Our model

Figure 10: Comparison between our model and two traditional models. (a) Blue lines denote the pressure transient behaviors of a falloff test computed by a single-phase model in a single-well system. Black lines are the pressure transient behaviors of a falloff test computed by a two-phase model in a single-well system. (b) Red lines denote the pressure transient behaviors of a falloff test computed by our model.

keep a good agreement, indicating that the accuracy of our model is satisfactory.

\section{Results and Discussion}

In this section, we introduce the type curve computed by our model and flow regimes of the pressure transient behavior of a falloff test with interference from two adjacent injectors firstly. Then, our models, model of single-phase flow in a single-well system and model of two-phase flow in a singlewell system, are compared to illustrate the novelty of our model. After that, seven cases are crafted to investigate the effect of model parameters on pressure transient behavior. More specifically, five parameters influencing the transitional zone (i.e., duration of water injection, injection rate of testing well, initial water saturation, type of relative permeability, and radius of inner region) and two parameters of adjacent injectors (i.e., rate of adjacent injector and well spacing) are analyzed.

4.1. Type Curve and Model Comparison. Figure 9 illustrates the type curve of a falloff test with the interference of two adjacent injectors, which is generated from our two-phase numerical model. The rates of the two adjacent injectors remain constant during the whole procedure of the falloff test. We divide the type curve into seven flow regimes according to its characteristics. After the flow regime of wellbore storage and damage, the duration of first radial flow regime is predominated by the flow of the zone completely flooded by water. Then, the flow regime of the transitional zone depends on the saturation gradients derived from water injection prior to shut-in. The average water saturation of the transitional zone is smaller than that of the zone completely flooded by water, resulting in smaller water relative permeability and larger oil relative permeability than that of the zone completely flooded by water. In this scenario, the average water saturation of the transitional zone is larger than the average oil saturation due to water injection before shut-in. Hence, the water relative permeability has a greater impact on the total mobility of the transitional zone, and the total mobility of the transitional zone is smaller than that of the zone completely flooded by water, leading to the upward moving of pressure derivative curve. After that, the second radial flow regime reflects the flow of the unflooded zone. Subsequently, the transitional flow regime of formation damage is generated from the permeability difference of the inner zone and outer zone. The radial flow regime of the outer zone is covered by the flow regime of interwell interference, in which two adjacent injectors start to affect the pressure response of the testing injector by replenishing the formation energy, leading to the sharp downward movement of the pressure derivative curve.

To further illustrate the specialty of our model, three scenarios are crafted for comparison. Note that the relative permeability and viscosity of the single-phase flow in a single-well system are the average values calculated according to the parameters of the two-phase flow in Figure 10(a). As illustrated in Figure 10(a), the radial flow regime of the inner zone of the two-phase flow is divided into two parts by the flow regime of the transitional zone. Additionally, the water saturation in the near-well region of the twophase flow increases significantly due to water injection before shut-in, leading to the increase of water relative permeability and the decrease of oil relative permeability. The water relative permeability has a greater effect on the total mobility of the zone flooded by water due to high water saturation of this zone, leading to a smaller total mobility of two-phase flow than that of single-phase flow in the zone flooded by water. Therefore, the pressure drop of the twophase flow is smaller than that of the single-phase flow before the radial flow regime of the outer zone.

Figure 10(b) illustrates that the pressure derivative curve moves downward drastically after the transitional flow 


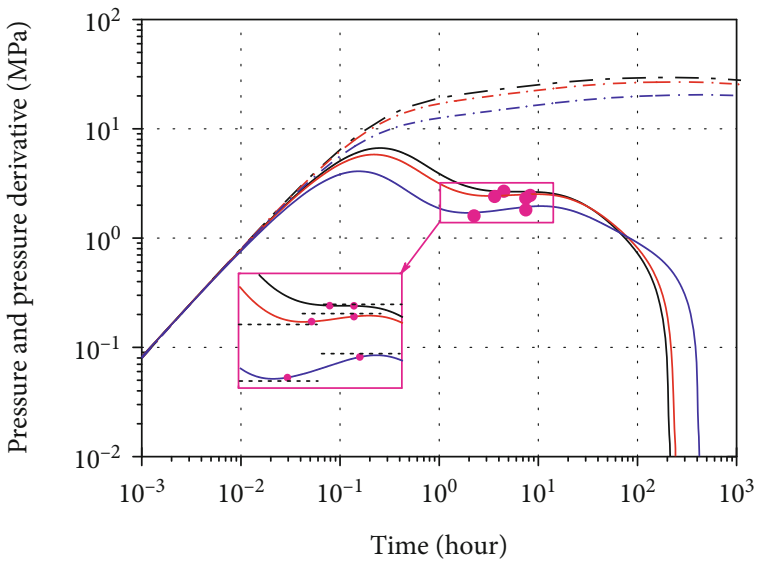

$$
\begin{aligned}
-t_{1} & =5 \mathrm{~d} \\
-t_{1} & =10 \mathrm{~d} \\
-t_{1} & =50 \mathrm{~d}
\end{aligned}
$$

FIGURE 11: Effect of injection time on pressure transient response. $t_{1}$ is the injection time of testing well.

regime of formation damage when the interference effect of the two adjacent wells is taken into account.

The comparisons in Figure 10 further demonstrate that it would lead to errors in well test interpretation if the effect of saturation gradients or the impact caused by adjacent injectors is ignored.

4.2. Transitional Zone. To investigate the characteristics of the flow regime of the transitional zone, the effect of five parameters on the characteristics is analyzed, including the duration of water injection, injection rate of testing well, initial water saturation, type of relative permeability, and radius of inner region. In these cases, a testing injector and two neighboring injectors are located in a $40000 \mathrm{~m} \times 40000 \mathrm{~m} \times$ $10 \mathrm{~m}$ reservoir model with hybrid grids (i.e., regular Cartesian and radial grids); the radius of each wellbore grid is $2.8 \mathrm{~m}$, and well spacings $\left(L_{1}, L_{2}\right)$ are $500 \mathrm{~m}$. The injection rates of the two adjacent injectors remain constant during the falloff test. Shut-in time for the testing well $\left(t_{2}\right)$ is $42 \mathrm{~d}$. The permeability of the inner region $\left(K_{1}\right)$ is $0.1 \mathrm{D}$, the permeability of the outer region $\left(K_{2}\right)$ is $0.3 \mathrm{D}$, and wellbore storage constant is $0.1 \mathrm{~m}^{3} / \mathrm{MPa}$. Some basic input parameters are listed in Table 1.

4.2.1. Duration of Water Injection. In this case, the injection rate of the testing well $\left(q_{w}\right)$ before shut-in is $200 \mathrm{~m}^{3} / \mathrm{d}$; the injection rates of the two adjacent injectors $\left(q_{1}, q_{2}\right)$ are both $400 \mathrm{~m}^{3} /$ d. The initial water saturation $\left(S_{w i}\right)$ is 0.5 . Relative permeability curves are shown in Figure 7. Radius of inner region $(r)$ is $50.47 \mathrm{~m}$. Figure 11 illustrates that the characteristics of the flow regime of the transitional zone are more significant with the extension of injection time because of the expansion of the transitional zone. In addition, the characteristics of this regime are recognizable when the water injection time $\left(t_{1}\right)$ reaches $10 \mathrm{~d}$, indicating that the flow regime of the transitional zone is common in the pressure transient behavior of injectors located in oilfields of moderate permeability.

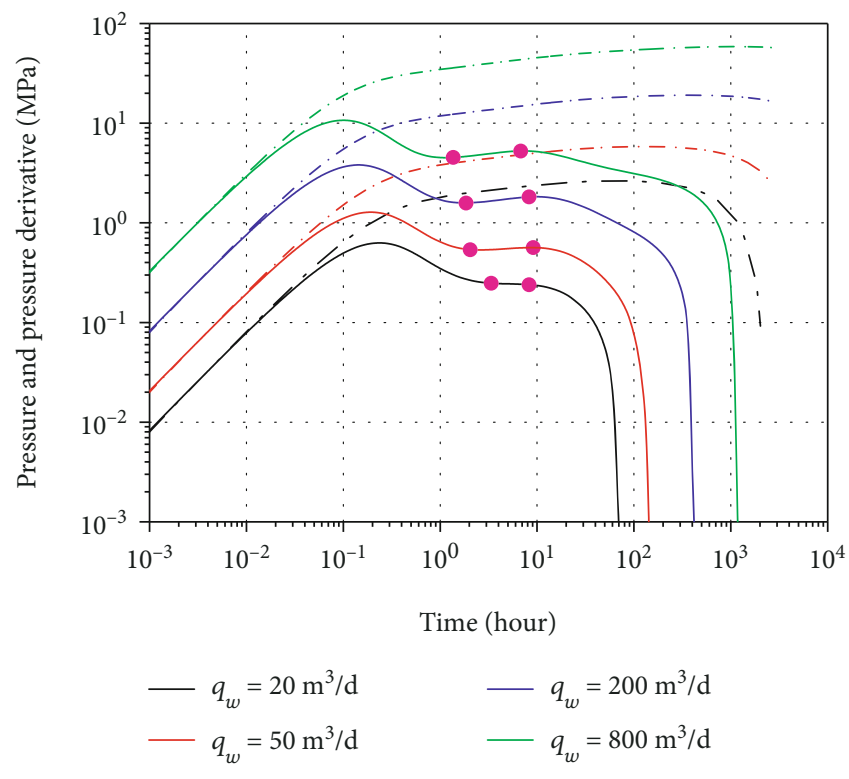

FIGURE 12: Effect of injection rate on pressure transient response. $q_{w}$ is the injection rate of testing well before shut-in.

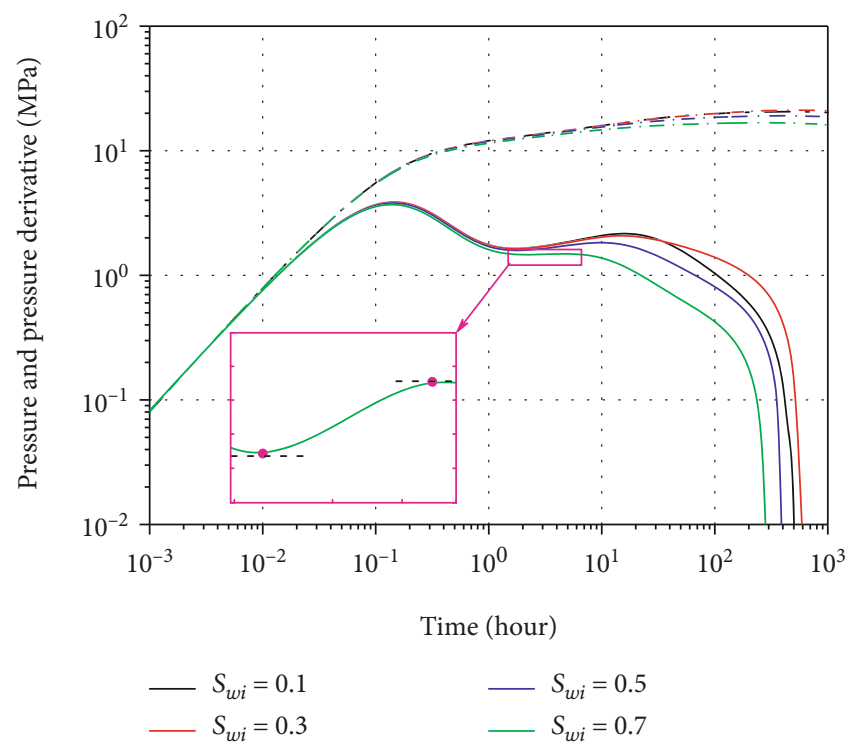

FIgURE 13: Effect of initial water saturation on pressure transient response. $S_{w i}$ is the initial water saturation.

4.2.2. Injection Rate of Testing Well. In this scenario, $q_{1}=q_{2}$ $=400 \mathrm{~m}^{3} / \mathrm{d}, r=50.47 \mathrm{~m}, S_{w i}=0.5$, and $t_{1}=50 \mathrm{~d}$. Relative permeability curves are shown in Figure 7. Figure 12 illustrates that the characteristics of the flow regime of the transitional zone become more obvious with the increase of injection rate because of the expansion of the transitional zone. Additionally, the characteristics of this regime are distinct when the injection rate $\left(q_{w}\right)$ reaches $50 \mathrm{~m}^{3} / \mathrm{d}$, which illustrates that the flow regime of the transitional zone is common in the pressure transient response of injectors in oilfields of moderate permeability. 


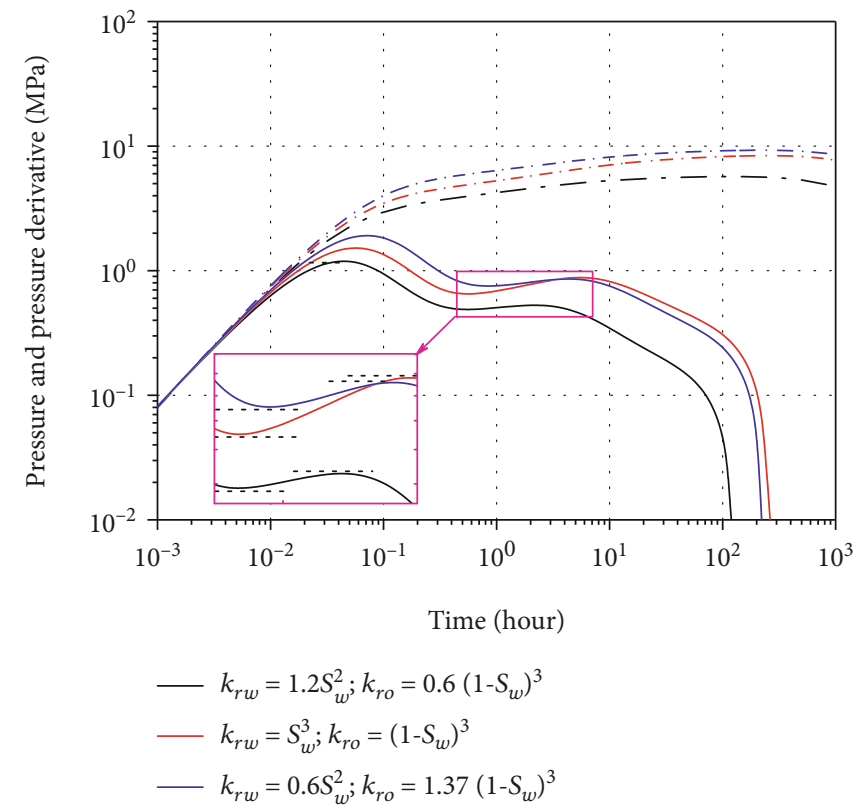

(a)

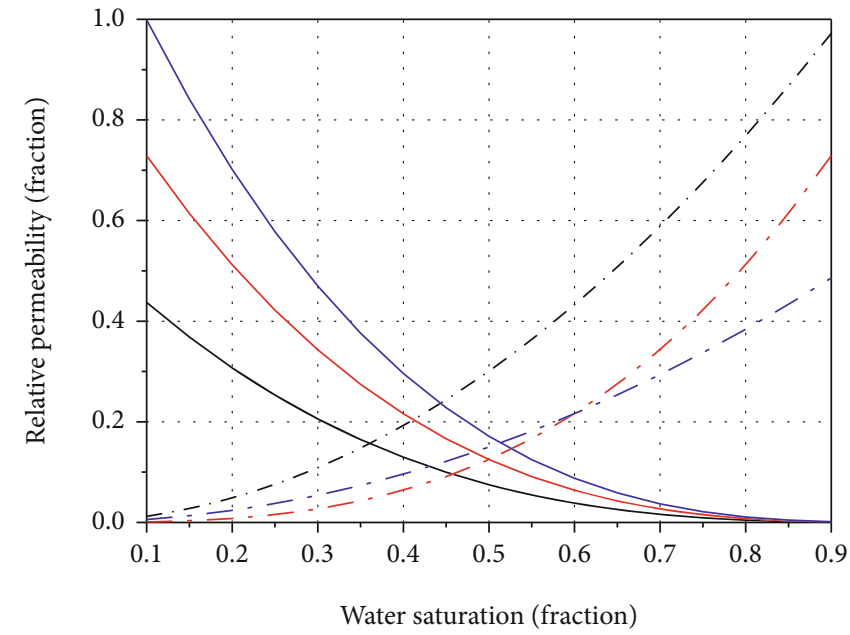

$$
\begin{aligned}
& \cdots k_{r w}=1.2 S_{w}^{2} \quad-k_{r o}=\left(1-S_{w}\right)^{3} \\
& -k_{r o}=0.6\left(1-S_{w}\right)^{3} \quad-\cdot-k_{r w}=0.6 S_{w}^{2} \\
& \text {-.- } k_{r w}=S_{w}^{3} \quad-k_{r o}=1.37\left(1-S_{w}\right)^{3}
\end{aligned}
$$

(b)

FIGURE 14: Effect of type of relative permeability on pressure transient response: (a) pressure transient response of the testing well with three different types of relative permeability; (b) three different types of relative permeability.

4.2.3. Initial Water Saturation. It is necessary to analyze the initial water saturation because the relative permeability is a function of water saturation. Most of the parameters of this case are the same as those of the scenario in Section 4.2.2. The injection rate $\left(q_{w}\right)$ of the testing well is $200 \mathrm{~m}^{3} / \mathrm{d}$. Figure 13 shows that the characteristics of the flow regime of the transitional zone are less obvious with the increase of initial water saturation. This is because the increase of water saturation is limited during water injection when the initial water saturation is close to the maximum value of the oilfield, resulting in the shrinking of the transitional zone.

4.2.4. Type of Relative Permeability. We designate three different types of relative permeability to analyze their influence on the characteristics of the flow regime of the transitional zone, which are shown in Figure 14(b). In this scenario, $q_{w}=200 \mathrm{~m}^{3} / \mathrm{d}, \quad q_{1}=q_{2}=400 \mathrm{~m}^{3} / \mathrm{d}, \quad r=50.47 \mathrm{~m}$, $S_{w i}=0.5$, and $t_{1}=50 \mathrm{~d}$. As shown in Figure 14(a), with the three different types of relative permeability, the characteristics of the flow regime of the transitional zone are significant.

4.2.5. Radius of Inner Region. In this scenario, most of the parameters of this case are the same as those of the scenario in Section 4.2.4. Relative permeability curves are shown in Figure 7. Figure 15 shows that the characteristics of the flow regime of the transitional zone are obvious when the radius of the inner region reaches $50.47 \mathrm{~m}$. The characteristics could be covered by the transitional flow regime generated from formation damage when the radius of the inner region is small. Hence, the characteristics may be ignored in pressure transient analysis. However, the ignorance of the characteristics would lead to erroneous results in well test interpretation.

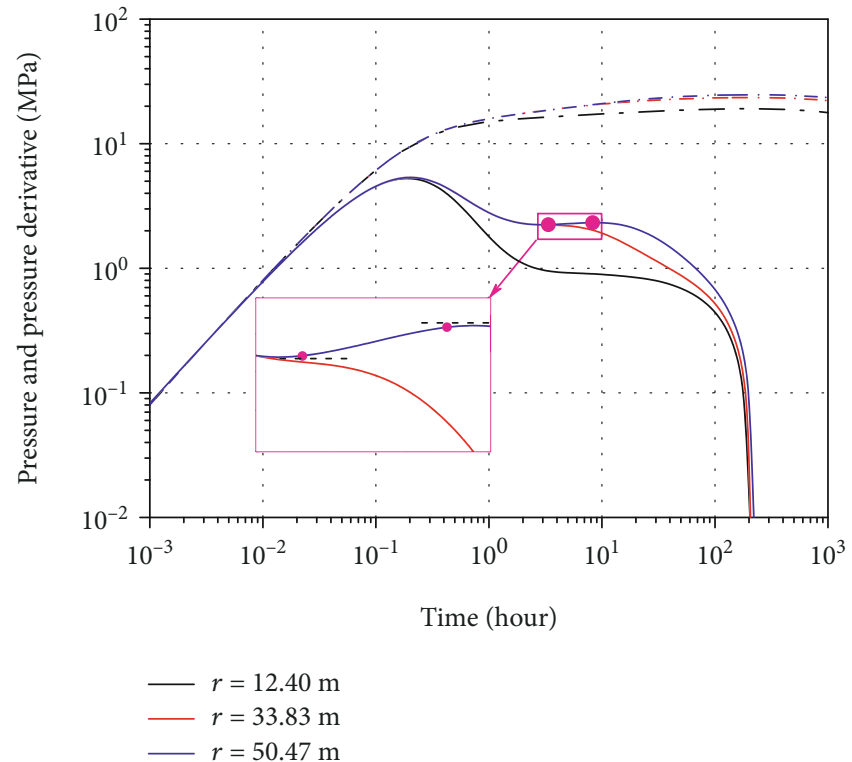

Figure 15: Effect of radius of the inner region on the pressure transient response. $r$ denotes the radius of the inner region.

4.3. Adjacent Injectors. Two scenarios are crafted to investigate the impact of the rate of the adjacent injector and well spacing on the pressure transient behavior of the testing well. The difference of well spacings in the flood patterns is usually not sufficient to distinguish which well the interference is coming from in pressure transient analysis. Therefore, we just discuss the scenarios that well spacings $\left(L_{1}=L_{2}\right)$ or rates of adjacent injectors $\left(q_{1}=q_{2}\right)$ are distributed uniformly. The reservoir models are the same as those of Section 4.2. 


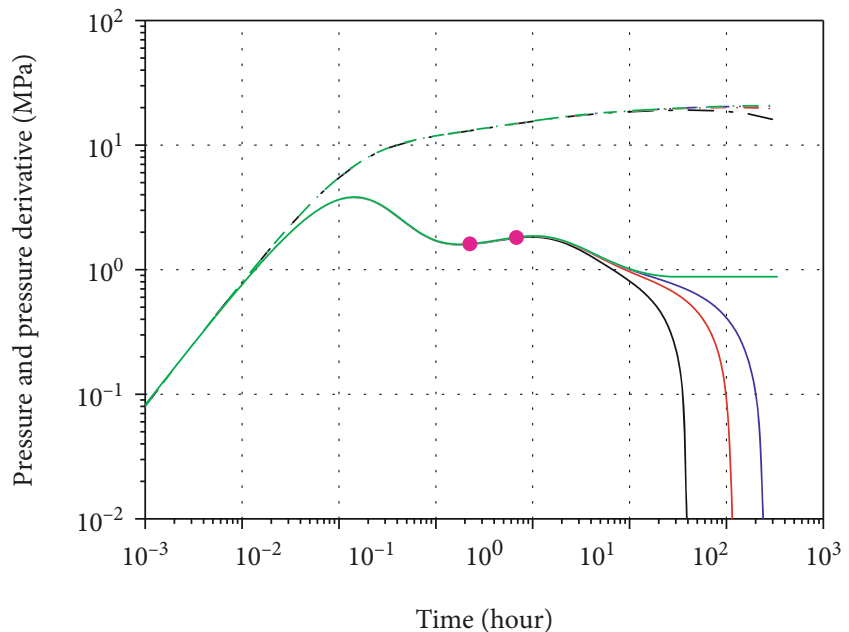

$$
\begin{aligned}
& -q_{1}=q_{2}=400 \mathrm{~m}^{3} / \mathrm{d} \quad-q_{1}=q_{2}=20 \mathrm{~m}^{3} / \mathrm{d} \\
& -q_{1}=q_{2}=100 \mathrm{~m}^{3} / \mathrm{d} \quad-q_{1}=q_{2}=0 \mathrm{~m}^{3} / \mathrm{d}
\end{aligned}
$$

Figure 16: Effect of the rate of the adjacent injector on pressure transient response. $q_{1}$ and $q_{2}$ are the rates of adjacent injectors.

4.3.1. Rate of Adjacent Injector. In this scenario, $q_{w}=200$ $\mathrm{m}^{3} / \mathrm{d}, q_{1}=q_{2}=400 \mathrm{~m}^{3} / \mathrm{d}, \quad r=50.47 \mathrm{~m}, S_{w i}=0.5, t_{1}=50 \mathrm{~d}$, $t_{2}=139 \mathrm{~d}$, and $L_{1}=L_{2}=500 \mathrm{~m}$. Relative permeability curves are illustrated in Figure 7. Figure 16 shows that the flow regime of interwell interference appears later as the rates of the two adjacent injectors decrease. The transitional flow regime of formation damage is difficult to be covered up because the well spacing is usually much larger than the radius of the formation damage zone in offshore oilfields.

4.3.2. Well Spacing. Most of the parameters of this scenario are the same as those of the scenario in Section 4.2.5; the rates of adjacent injectors are $400 \mathrm{~m}^{3} / \mathrm{d}$. As shown in Figure 17, the flow regime of interwell interference appears earlier as well spacings decrease.

\section{Field Application}

To obtain accurate results in a well test interpretation, we must choose an appropriate model for history matching according to the geological information and characteristics of flow regimes in pressure and pressure derivative curves. Researchers mainly focused on models for single-phase flow in single-well systems in the past. Now, it has been demonstrated that the characteristics of the flow regimes of the transitional zone and the interference from adjacent injectors cannot be ignored in pressure transient analysis.

This section is to illustrate that our two-phase numerical model for multiwell systems is accurate and practical. Therefore, we interpret the pressure data from a testing injector in a Chinese offshore oilfield with two traditional models and our model.

5.1. Basic Information of a Testing Injector in a Chinese Offshore Oilfield. The basic parameters of a testing injector

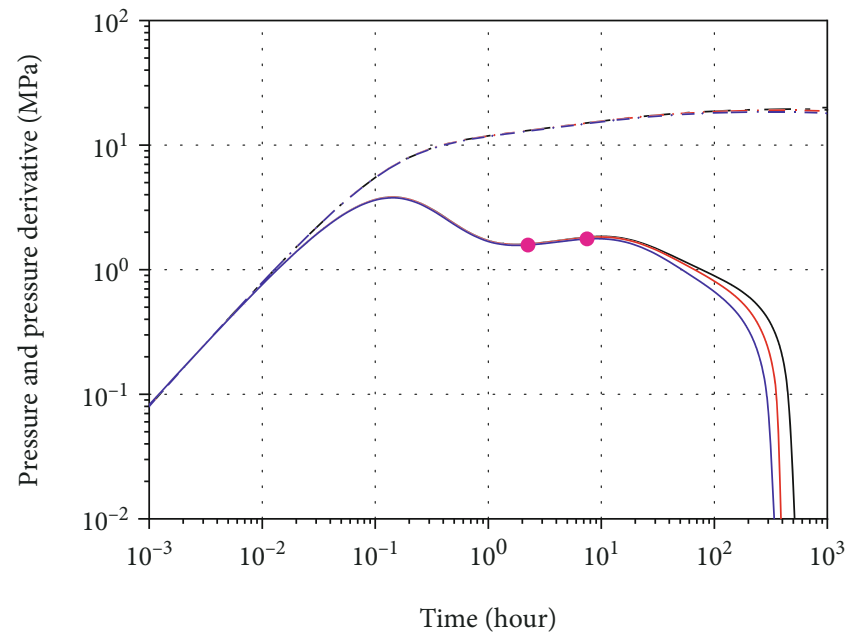

$$
\begin{aligned}
-L_{1} & =L_{2}=900 \mathrm{~m} \\
-L_{1} & =L_{2}=500 \mathrm{~m} \\
L_{1} & =L_{2}=100 \mathrm{~m}
\end{aligned}
$$

FIgURE 17: Effect of well spacing on pressure transient response. $L_{1}$ and $L_{2}$ are well spacings.

TABLE 2: The basic parameters of a field case.

\begin{tabular}{lc}
\hline Parameters & Values \\
\hline Porosity, fraction & 0.28 \\
Rock compressibility, $\mathrm{MPa}^{-1}$ & $4.64 \times 10^{-4}$ \\
Permeability from well log, D & 0.285 \\
Thickness, m & 18.5 \\
Initial oil saturation, fraction & 0.64 \\
Water viscosity, $\mathrm{mPa} \cdot \mathrm{s}$ & 0.49 \\
Oil viscosity, $\mathrm{mPa} \cdot \mathrm{s}$ & 3.1 \\
Water compressibility, $\mathrm{MPa}^{-1}$ & $4.64 \times 10^{-4}$ \\
Oil compressibility, $\mathrm{MPa}^{-1}$ & $4.56 \times 10^{-4}$ \\
Water volume factor, $\mathrm{m}^{3} / \mathrm{m}^{3}$ & 1.012 \\
Oil volume factor, $\mathrm{m}^{3} / \mathrm{m}^{3}$ & 0.9 \\
Well radius, $\mathrm{m}$ & 0.122 \\
Injection rate of testing well, $\mathrm{m}^{3} / \mathrm{d}$ & 90 \\
Injection rate of adjacent well $\left(q_{1}\right), \mathrm{m}^{3} / \mathrm{d}$ & 117 \\
Injection rate of adjacent well $\left(q_{2}\right), \mathrm{m}^{3} / \mathrm{d}$ & 133 \\
Well spacing $\left(L_{1}\right), \mathrm{m}$ & 350 \\
Well spacing $\left(L_{2}\right), \mathrm{m}$ & 350 \\
\hline
\end{tabular}

in a line drive pattern of a Chinese offshore oilfield are shown in Table 2. The relative permeability curves are illustrated in Figure 7. The injection time of the testing well is $1200 \mathrm{~h}$; shutin time is $106.43 \mathrm{~h}$. Rates of two adjacent injectors remain constant during the falloff test. Acidizing treatment was employed to remove near-well plugging every year because the injection pressure of this well increased abnormally.

5.2. Well Test Interpretation with Traditional Models. Two traditional models of a single-well system are used for history 


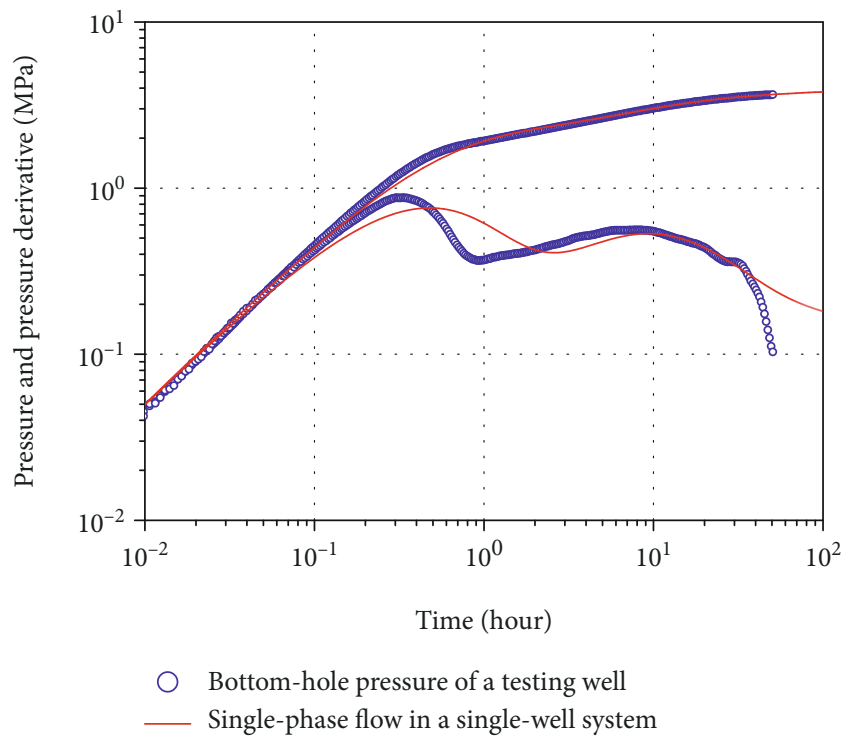

(a)

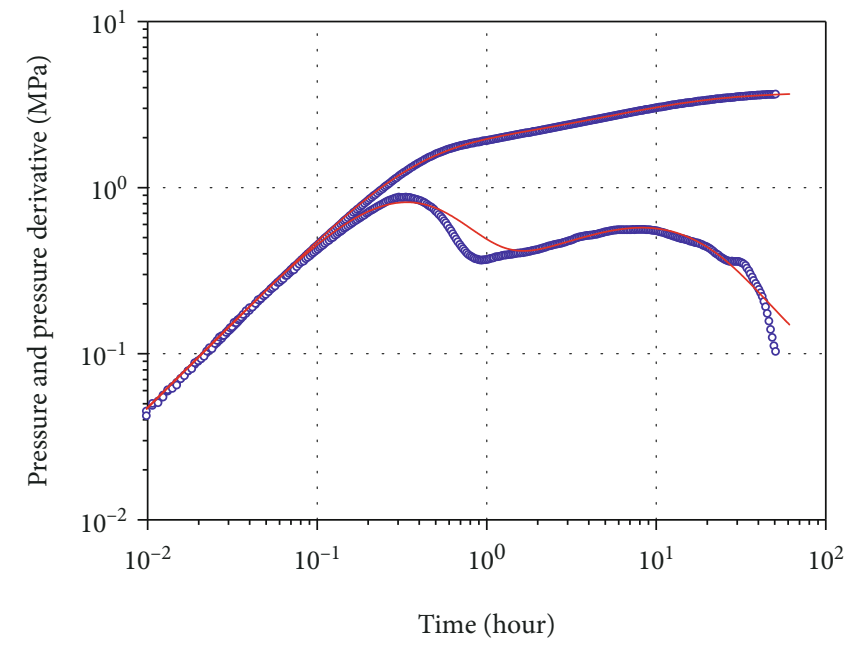

Bottom-hole pressure of a testing well

_ Two-phase flow in a single-well system

(b)

FIGURE 18: History matching results computed by two traditional models: (a) history matching using the composite model for single-phase flow in a single-well system; (b) history matching using the composite model for two-phase flow in a single-well system.

matching in this section, including a single-phase composite model and a two-phase composite model. Figure 18(a) illustrates the pressure curves of the single-phase composite model can only match with the pressure data during the flow regime of wellbore storage and the transitional flow regime of formation damage, which are unable to match the curves of the flow regime of transitional zone and the flow regime of interwell interference. As shown in Figure 18(b), the results computed by the two-phase composite model match well with the pressure data except for the flow regime of interference.

5.3. Well Test Interpretation with Our Model. For our model in this paper, the matching procedure includes the following three steps.

Step 1. Input the pressure data of the testing injector and basic parameters listed in Section 5.1 into the program that we compiled based on our model.

Step 2. Set the range of unknown parameters. To reduce the matching time, we can limit the range of certain parameters based on field geologic and dynamic information. For instance, the permeabilities of two zones should change from 0 to $0.285 \mathrm{D}$ in this interpretation according to the permeability derived from well log. The permeability of the inner zone (formation damage zone) should be smaller than that of the outer zone due to formation damage in the nearwell zone.

Step 3. Adjust the unknown parameters according to the features discussed in the sensitivity analysis. For instance, the characteristics of the flow regimes of the transitional zone and interference from adjacent injectors are significant and

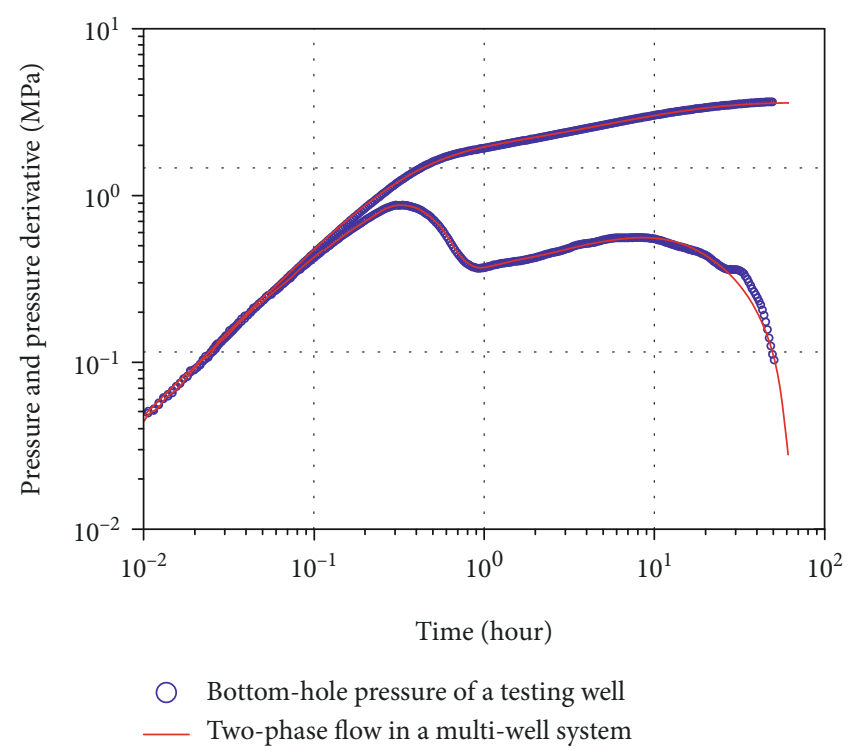

FIGURE 19: History matching results computed by our model.

recognizable. Hence, the uncertain parameters can be adjusted according to the features of different flow regimes to match the pressure data from the testing well.

As shown in Figure 19, the pressure curves computed by our model match well with the pressure data of the testing well, which verifies the applicability of our model. The interpretation results are shown in Table 3 . The radius of formation damage zone is $40.21 \mathrm{~m}$; the permeability of formation damage zone is $0.035 \mathrm{D}$. 
TABLE 3: Interpretation results generated from our model.

\begin{tabular}{lc}
\hline Interpreting parameters & Values \\
\hline Wellbore storage constant of injector, $\mathrm{m}^{3} / \mathrm{MPa}$ & 0.8 \\
Skin factor of injector, unitless & -0.8 \\
Radius of inner zone (formation damage zone), $\mathrm{m}$ & 40.21 \\
Permeability of inner zone (formation damage zone), D & 0.035 \\
Permeability of outer zone, D & 0.115 \\
\hline
\end{tabular}

\section{Conclusions}

To characterize the formation damage in near-well regions of injection wells, we developed a two-phase model to simulate the pressure transient behavior of a water injection well in the multiwell system. A hybrid grid system consisting of both Cartesian and radial meshes was employed in discretizing partially differential flow equations to compute our model more efficiently. The model was validated by comparing with a commercial simulator. To demonstrate the applicability of the model, we interpreted the pressure data derived from a testing injector with formation damage in the near-well region, which is located in the line drive pattern of a Chinese offshore oilfield. The investigation of our model led to the following conclusions:

(1) New flow regimes can be observed on the type curve, including the flow regime of the transitional zone and flow regime of interwell interference. The pressure derivative curve moves upward during the flow regime of the transitional zone and moves downward during the flow regime of interwell interference. The pressure drop of our model is smaller than that of the single-phase model before the radial flow regime of the outer zone

(2) Duration of water injection, injection rate of testing well, initial water saturation, and radius of the inner region have a great influence on the characteristics of the flow regime of transitional zone established by water injection. Duration of water injection, injection rate of testing well, and initial water saturation can affect the expansion of the transitional zone. The flow regime of the transitional zone will be covered by the flow regime of formation damage when the radius of the inner region is small enough

(3) Ignoring the effects of saturation gradients and interference from adjacent injectors on the pressure response of testing injectors located in the line drive pattern will cause errors in well test interpretation

\section{Nomenclature}

$\begin{array}{ll}\phi: & \text { Rock porosity, fraction } \\ \alpha: & \text { Oil or water phase } \\ o: & \text { Oil phase } \\ w: & \text { Water phase }\end{array}$

$S_{\alpha}: \quad$ Oil or water saturation, fraction

$b_{\alpha}$ : Reciprocal of the oil/water formation volume factor, $\mathrm{m}^{3} / \mathrm{m}^{3}$

$p_{\alpha}: \quad$ Oil or water pressure in reservoir, $\mathrm{MPa}$

$v_{\alpha}$ : $\quad$ Velocity of oil or water phase in porous media, $\mathrm{m}^{3} / \mathrm{s}$

$Q_{\alpha}$ : $\quad$ Well flux of phase $\alpha, \mathrm{m}^{3} / \mathrm{d}$

$K: \quad$ Absolute permeability of reservoir, D

$k_{r \alpha}$ : $\quad$ Relative permeability of phase $\alpha$, fraction

$\mu_{\alpha}$ : Viscosity of phase $\alpha, \mathrm{mPa} \cdot \mathrm{s}$

$\rho_{\alpha}: \quad$ Density of phase $\alpha, \mathrm{kg} / \mathrm{m}^{3}$

$g: \quad \quad$ Gravity acceleration, $\mathrm{m} / \mathrm{s}^{2}$

$x, y, z: \quad$ Coordinates in different directions

$Q_{s}: \quad \quad \quad$ Total well flux of oil and water, $\mathrm{m}^{3} / \mathrm{d}$

$\lambda_{\alpha}$ : $\quad$ Ratio of relative permeability to viscosity for phase $\alpha$

$h: \quad$ Thickness of formation, $m$

$r_{e}: \quad$ Equivalent radius in well flux equation, $m$

$r_{w}: \quad$ Wellbore radius, $\mathrm{m}$

$S: \quad$ Skin factor, unitless

$p_{w f}: \quad$ Bottom-hole pressure, $\mathrm{MPa}$

C: $\quad$ Wellbore storage constant, $\mathrm{m}^{3} / \mathrm{MPa}$

$t: \quad$ Time, $s$

div: Divergence operator

grad: Gradient operator

q: $\quad$ Array of discrete fluxes, $\mathrm{m}^{3} / \mathrm{d}$

$f: \quad$ Face

$c: \quad$ Cell

$C_{1}(f)$ : Cell including face $f$

$C_{1}(f)$ : Cell including face $f$

p: $\quad$ Array of discrete pressures

T: $\quad$ Array of discrete transmissibilities across faces

$A_{i, k}: \quad$ Area of face, $\mathrm{m}^{2}$

$\vec{n}_{i, k}: \quad$ Normal from the centroid of interior face to cell $k$

$\vec{c}_{i, k}$ : Vector from the centroid of cell $i$ to the centroid of interior face

$\mathbf{K}_{i}: \quad$ Permeability tensor of cell $i$

$\vec{n}_{k, i}: \quad$ Vector from the centroid of cell $k$ to the centroid of interior face

$\vec{c}_{k, i}: \quad$ Normal from the centroid of interior face to cell $i$

$\mathbf{K}_{k}$ : $\quad$ Permeability tensor of cell $k$

$T_{i k}$ : Transmissibility of interior face

$T_{k, i}: \quad$ One-sided transmissibility from cell $k$ to cell $i$

$T_{i, k}$ : One-sided transmissibility from cell $i$ to cell $k$

$n: \quad$ Time step

$l$ : $\quad$ Iterating step

$\mathbf{R}_{\alpha}^{n+1, l}$ : $\quad$ Array of discrete form of conservation equation of phase $\alpha$ at the $l$ th iterating step of $n+1$ time step

$\mathbf{R}_{q}^{n+1, l}$ : $\quad$ Array of discrete form of well equation of phase $\alpha$ at the $l$ th iterating step of $n+1$ time step

$\mathrm{V}: \quad$ Array of volumes of grids

$\mathbf{X}^{n+1, l}$ : $\quad$ Array of primary variables at the $l$ th iterating step of $n+1$ time step

$\Delta \mathbf{X}^{n+1, l}: \quad$ Array of increment of primary variables at the $l^{\text {th }}$ iterating step of $n+1$ time step

$\phi: \quad$ Array of rock porosity

$\mathbf{S}_{\alpha}: \quad$ Array of oil or water saturation

$\mathbf{b}_{\alpha}$ : $\quad$ Array of inverse formation-volume factor of oil/water 


$\begin{array}{ll}\mathbf{v}_{\alpha}: & \text { Array of oil or water velocity in porous media } \\ \mathbf{Q}_{\alpha}: & \text { Array of well flux of phase } \alpha \\ \boldsymbol{\rho}_{\alpha}: & \text { Array of density of phase } \alpha \\ \lambda_{\alpha}: & \text { Array of ratio of relative permeability to viscosity } \\ & \text { for phase } \alpha \\ \mathbf{p}_{\alpha}: & \text { Array of oil or water pressure in reservoir } \\ \mathbf{p}_{w f}: & \text { Array of bottom-hole pressure } \\ \mathrm{IUV}: & \text { Relative incremental error } \\ \mathrm{MB}_{\alpha}: & \text { Relative mass-balance error } \\ \mathrm{MV}_{\alpha}: & \text { Maximum normalized residual } \\ \boldsymbol{\Phi}_{\alpha}: & \text { Array of quality of oil/water phase in cells } \\ r: & \text { Radius of inner zone, m } \\ \mathrm{W} 1, \mathrm{~W} 2: & \text { Abbreviation of wells } \\ q_{w}: & \text { Rate of the testing injector, } \mathrm{m}^{3} / \mathrm{d} \\ q_{1}, q_{2}: & \text { Rates of two adjacent injection wells, } \mathrm{m}^{3} / \mathrm{d} \\ t_{1}: & \text { Injection time for the testing well, } \mathrm{d} \\ t_{2}: & \text { Shut-in time for the testing well, } \mathrm{d} \\ L_{1}, L_{2}: & \text { Well spacings between the testing well and adja- } \\ K_{1}: & \text { cent injectors, m } \\ K_{2}: & \text { Permeability of inner zone, } \mathrm{D}\end{array}$

\section{Data Availability}

The data used to support the results of this study are available from the corresponding author upon request.

\section{Conflicts of Interest}

The authors declare no conflicts of interest.

\section{Acknowledgments}

The first author (CSC NO. 201906440163) would like to thank the China Scholarship Council for supporting this research at the University of Utah, USA.

\section{References}

[1] K. C. Khilar and H. S. Fogler, "Colloidally induced fines migration in porous media," Reviews in Chemical Engineering, vol. 4, no. 1-2, pp. 41-108, 1987.

[2] O. O. Eleri and J. R. Ursin, "Physical aspects of formation damage in linear flooding experiments," in SPE Formation Damage Control Symposium, Lafayette, Louisiana, 1992.

[3] C. Roque, G. Chauveteau, M. Renard, G. Thibault, M. Bouteca, and J. Rochon, "Mechanisms of formation damage by retention of particles suspended in injection water," in SPE European Formation Damage Conference, The Hague, Netherlands, 1995.

[4] Y. Shen, D. Liu, Y. Ji, and J. Chen, "The plugging mechanism of water injection wells in Chengbei And Suizhong 36-1 Oilfield Of Bohai," Oil Drilling \& Production Technology, vol. 1, 1998.

[5] H. Liu, "Experimental research on formation damage by cold water injection in Beixiaohu Oilfield," Journal of The University of Petroleum, China, vol. 5, 2001.

[6] H. Liu, G. Li, and Y. Li, "Simulation of formation damage after long term water flooding," in SPE Asia Pacific Oil and Gas Conference and Exhibition, Perth, Australia, 2012.

[7] I. M. Mohamed, G. I. Block, O. A. Abou-Sayed, S. M. Elkatatny, and A. S. Abou-Sayed, "Flow rate-dependent skin in water disposal injection well," Journal of Energy Resources Technology, vol. 138, no. 5, 2016.

[8] J. Li, X. Li, X. Wang et al., "Water distribution characteristic and effect on methane adsorption capacity in shale clay," International Journal of Coal Geology, vol. 159, pp. 135-154, 2016.

[9] F. Civan, Reservoir Formation Damage, Boston: Gulf Professional Publishing, 3rd edition, 2016.

[10] J. Li, X. Li, K. Wu et al., "Water sorption and distribution characteristics in clay and shale: effect of surface force," Energy \& Fuels, vol. 30, no. 11, pp. 8863-8874, 2016.

[11] J. Li, X. Li, K. Wu, D. Feng, T. Zhang, and Y. Zhang, “Thickness and stability of water film confined inside nanoslits and nanocapillaries of shale and clay," International Journal of Coal Geology, vol. 179, pp. 253-268, 2017.

[12] K. Prempeh, L. Chequer, A. Badalyan, and P. Bedrikovetsky, "Effects of kaolinite on fines migration and formation damage," in SPE International Conference and Exhibition on Formation Damage Control, Lafayette, Louisiana, USA, 2020.

[13] T. Loucks and E. Guerrero, "Pressure drop in a composite reservoir," Society of Petroleum Engineers Journal, vol. 1, no. 3, pp. 170-176, 1961.

[14] H. Bixel and H. Van Poollen, "Pressure drawdown and buildup in the presence of radial discontinuities," SPE Journal, vol. 7, no. 3, pp. 301-309, 1967.

[15] H. Ramey, "Approximate solutions for unsteady liquid flow in composite reservoirs," Journal of Canadian Petroleum Technology, vol. 9, no. 1, 1970.

[16] H. Kazemi, L. Merrill, and J. Jargon, "Problems in interpretation of pressure fall-off tests in reservoirs with and without fluid banks," Journal of Petroleum Technology, vol. 24, no. 9, pp. 1147-1156, 1972.

[17] L. Merrill, H. Kazemi, and W. B. Gogarty, "Pressure falloff analysis in reservoirs with fluid banks," Journal of Petroleum Technology, vol. 26, no. 7, pp. 809-818, 1974.

[18] A. Satman, M. Eggenschwiler, R. W. Tang, and H. J. Ramey Jr., "An analytical study of transient flow in systems with radial discontinuities," in SPE Annual Technical Conference and Exhibition, Dallas, TX, USA, January 1980.

[19] A. Al-Bemani and I. Ershaghi, "Two-phase flow interporosity effects on pressure transient test response in naturally fractured reservoirs," in SPE Annual Technical Conference and Exhibition, Dallas, Texas, January 1991.

[20] Q. Deng, R.-S. Nie, Y.-L. Jia et al., "Pressure transient behavior of a fractured well in multi-region composite reservoirs," Journal of Petroleum Science and Engineering, vol. 158, pp. 535553, 2017.

[21] Z. Chen, W. Yu, X. Liao, X. Zhao, Y. Chen, and K. Sepehrnoori, "A two-phase flow model for fractured horizontal well with complex fracture networks: transient analysis in flowback period," in SPE Liquids-Rich Basins Conference North America, Midland, Texas, USA, 2017.

[22] Y. He, J. Qin, S. Cheng, and J. Chen, "Estimation of fracture production and water breakthrough locations of multi-stage fractured horizontal wells combining pressure-transient analysis and electrical resistance tomography," Journal of Petroleum Science and Engineering, vol. 194, article 107479, 2020.

[23] H. G. Weinstein, "Cold waterflooding a warm reservoir," in Fall Meeting of the Society of Petroleum Engineers of AIME, Houston, Texas, 1974.

[24] A. Sosa, R. Raghavan, and T. J. Limon, "Effect of relative permeability and mobility ratio on pressure falloff behavior," 
Journal of Petroleum Technology, vol. 33, no. 6, pp. 1125-1135, 1981.

[25] N. S. Yeh and R. G. Agarwal, "Pressure transient analysis of injection wells in reservoirs with multiple fluid banks," in SPE Annual Technical Conference and Exhibition, San Antonio, Texas, 1989.

[26] G. M. Warren, "Numerical solutions for pressure transient analysis," in SPE Gas Technology Symposium, Calgary, Alberta, Canada, 1993.

[27] X. W. Liao and L. M. Liu, "Three-dimensional two-phase-flow numerical well testing model," Journal-University of Petroleum China Natural Science Edition, vol. 27, pp. 42-44, 2003.

[28] Z. P. Xiang, L. H. Zhang, and H. Chen, "Influence of the relative permeability curve on numerical well test curve of oilwater-phase flow," Journal of Southwest Petroleum University, vol. 29, 2007.

[29] W. Xu, Z. Liu, J. Liu, and Y. Yang, "New understanding of transient pressure response in the transition zone of oilwater and gas-water systems," Geofluids, vol. 2018, Article ID 1210950, 15 pages, 2018.

[30] L. G. Thompson and A. C. Reynolds, "Well testing for radially heterogeneous reservoirs under single and multiphase flow conditions," SPE Formation Evaluation, vol. 12, no. 1, pp. 57-64, 1997.

[31] Y. Jian and L. Xin, "Influence of interwell heterogeneity mode on water flooding effectiveness at high water cut stage," FaultBlock Oil \& Gas Field, vol. 2, 2012.

[32] L. Li, J. Yao, Y. Li, M. Wu, and L. Zhang, "Pressure-transient analysis of $\mathrm{CO}_{2}$ flooding based on a compositional method," Journal of Natural Gas Science and Engineering, vol. 33, pp. 30-36, 2016.

[33] W. Ouyang, D. Yang, and H. Sun, "Transient pressure analysis in partially perforated vertical wells," Proceedings of the International Field Exploration and Development Conference 2018. IFEDC 2018, Springer Series in Geomechanics and Geoengineering, J. Lin, Ed., Springer, Singapore, 2018.

[34] M. Onur, K. V. Serra, and A. C. Reynolds, "Analysis of pressure-buildup data from a well in a multiwell system," SPE Formation Evaluation, vol. 6, no. 1, pp. 101-110, 1991.

[35] J. Lin, Pressure Buildup Analysis for a Well in a PressureMaintained System, Society of Petroleum Engineers of AIME, Richardson, TX, USA, 1993.

[36] P. U. Giegbefumwen and E. S. Adewole, "Interference test pressures of a reservoir with vertical and horizontal wells," in SPE Nigeria Annual International Conference and Exhibition, Lagos, Nigeria, 2015.

[37] Y. He, S. Cheng, J. Qin et al., "Interference testing model of multiply fractured horizontal well with multiple injection wells," Journal of Petroleum Science and Engineering, vol. 176, pp. 1106-1120, 2019.

[38] J. Qin, S. Cheng, P. Li, Y. He, X. Lu, and H. Yu, "Interference well-test model for vertical well with double-segment fracture in a multi-well system," Journal of Petroleum Science and Engineering, vol. 183, article 106412, 2019.

[39] L. H. Zhang, Z. P. Xiang, Y. Li, and Q. G. Liu, "The inter-well interference effect on numerical well test curve of oil-waterph," Journal of Hydrodynamics (Series A), vol. 6, p. 17, 2006.

[40] B. A. Al-Wehaibi, M. B. Issaka, and A. Abuhasson, "Monitoring through analyzing real time build-up data from an intelligent field," in SPE Intelligent Energy International Conference and Exhibition, Aberdeen, Scotland, UK, 2016.
[41] A. S. Odeh, "Comparison of solutions to a three-dimensional black-oil reservoir simulation problem (includes associated paper 9741)," Journal of Petroleum Technology, vol. 33, no. 1, pp. 13-25, 1981.

[42] S. H. Lee, C. L. Jensen, and M. F. Lough, "An efficient finite difference model for flow in a reservoir with multiple length-scale fractures," in SPE Annual Technical Conference and Exhibition, Houston, Texas, 1999.

[43] T. Ertekin, J. H. Abou-Kassem, and G. R. King, Basic Applied Reservoir Simulation, vol. 7, Society of Petroleum Engineers, Richardson, TX, 2001.

[44] R. Hernandez and I. Illimani, "Numerical reservoir simulation coupled with geomechanics state of the art and application in reservoir characterization," in SPE Annual Technical Conference and Exhibition, Denver, Colorado, USA, 2011.

[45] J. Zhan, Y. Han, A. Fogwill et al., "A novel integrated numerical simulation scheme for transient gas flow in shale matrix," in SPE Symposium: Production Enhancement and Cost Optimisation, Kuala Lumpur, Malaysia, 2017.

[46] J. Zhan, "An integrated multi-scale numerical simulation of transient gas flow in shale matrix," in Offshore Technology Conference Asia, Kuala Lumpur, Malaysia, 2018.

[47] J. Xu, B. Chen, B. Sun, and R. Jiang, "Flow behavior of hydraulic fractured tight formations considering pre-Darcy flow using EDFM," Fuel, vol. 241, pp. 1145-1163, 2019.

[48] H. Zhong, H. Liu, T. Cui et al., "Numerical simulations of polymer flooding process in porous media on distributed-memory parallel computers," Journal of Computational Physics, vol. 400, article 108995, 2020.

[49] L. J. Durlofsky, "A triangle based mixed finite element-finite volume technique for modeling two phase flow through porous media," Journal of Computational Physics, vol. 105, no. 2, pp. 252-266, 1993.

[50] H. T. M. Van der Maarel and P. W. Hemker, "Structured adaptive finite-volume multigrid for compressible flows," in Fast Solvers for Flow Problems. Notes on Numerical Fluid Mechanics (NNFM), W. Hackbusch and G. Wittum, Eds., pp. 14-37, Vieweg+Teubner Verlag, Wiesbaden, 1995.

[51] P. Jenny, S. H. Lee, and H. A. Tchelepi, "Multi-scale finitevolume method for elliptic problems in subsurface flow simulation," Journal of Computational Physics, vol. 187, no. 1, pp. 47-67, 2003.

[52] H. Hajibeygi, G. Bonfigli, M. A. Hesse, and P. Jenny, "Iterative multiscale finite-volume method," Journal of Computational Physics, vol. 227, no. 19, pp. 8604-8621, 2008.

[53] M. Cancelliere and F. Verga, "Simulation of unconventional well tests with the finite volume method," Petroleum Science, vol. 9, no. 3, pp. 317-329, 2012.

[54] G. Galindez-Ramirez, M. R. A. Souza, D. K. E. Carvalho, and P. R. M. Lyra, "Numerical simulation of 1-D oil and water displacements in petroleum reservoirs using the spectral finite volume method," Journal of the Brazilian Society of Mechanical Sciences and Engineering, vol. 39, no. 7, pp. 2687-2700, 2017.

[55] M. HosseiniMehr, R. Arbarim, M. Cusini, C. Vuik, and H. Hajibeygi, "Algebraic dynamic multilevel method for fractured geothermal reservoir simulation," in SPE Reservoir Simulation Conference, Galveston, Texas, USA, 2019.

[56] J. E. Aarnes, T. Gimse, and K. A. Lie, "An introduction to the numerics of flow in porous media using Matlab," in Geometric modelling, numerical simulation, and optimization, G. Hasle, 
K. A. Lie, and E. Quak, Eds., pp. 265-306, Springer, Berlin, Heidelberg, 2007.

[57] K. A. Lie, An Introduction to Reservoir Simulation Using MATLAB/GNU Octave: User Guide for the MATLAB Reservoir Simulation Toolbox (MRST), Cambridge University Press, 2019.

[58] S. Krogstad, K.-A. Lie, O. Møyner, H. M. Nilsen, X. Raynaud, and B. Skaflestad, "MRST-AD-an open-source framework for rapid prototyping and evaluation of reservoir simulation problems," in SPE Reservoir Simulation Symposium, Houston, TX, 2015. 